\title{
Adult Autism - Global Challenge of the Future
}

Elona Mano, PhD. Cand.

\author{
Europian University of Tirana, Albania \\ kristinamano@yahoo.com
}

\begin{abstract}
There is an increase awareness of Autism Spectrum Disorder recently. The truth is that tens of thousands face an autism diagnosis each year. Even though the integration of autistic children is the focus of many studies in the last decades, the problem remains unsolved. What happens with autistic children as adults? In addition, one of the biggest challenges in providing services to people with an autism spectrum disorder is that the needs change from person to person. This study is focused on parent's point of view. During the interviews the participants raised some important issues. To have their children in the same classes with non-disabled children, was the first won battle of parents of autistic children, but integrating autistic individuals as adults in society seems to be just the cover of a big dilemma for parents of autistic children. Autistic child as adult is a real challenge for society worldwide.
\end{abstract}

Keyword: autism, society, child, adult, law

\section{Introduction}

Today in USA 1 in 91 new born is diagnosed with autism spectrum disorder (Kurti, V.2013). Even though the main source of the latest statistics is USA, autism is a global phenomenon. Recently a worldwide study was conducted. Based on the evidence reviewed, the median of prevalence estimates of autism spectrum disorders was $62 / 10000$. While existing estimates were variable, the evidence reviewed did not support differences in PDD (Pervasive Development Disorder) prevalence by geographic region nor of a strong impact of ethnic/cultural or socioeconomic factors (Elsabbagh, M. et al.2012).

Autism is a debated issue. There are a lot of studies on etiology of autism, but the real cause of autism is still unknown. One of the recent studies confirms that autism risks increase with mom's age. Mothers over 40 compared to mothers aged $20-30$, have $50 \%$ risk to have autistic children (Kurti, V.2010). Another big issue is the relation of autism with MMR vaccination. Jenny McCarthy, a mother of an ex-autistic child confesses this relation, but she still is not against vaccination. She is for vaccination, but before vaccination every child is better to do some analysis in order to decide when the child should be vaccinated. Still Kanner's idea of 'fridge mothers' remains a good point to raise hypothesis. Microanalysis studies have shown a close cooperation between infant and mother during first four months of age. Mother's face expressions indicated children's reactions (Vasta, R \& Haith, M. M \&Miller, A.S.2007). Another source of autism disorder is believed to be the environment pollution (Kurti, V.2013). Taking in consideration all we said above, it seems that the debate around autism is still a kind of natue-nurture problem.

The spectrum of disorder is wide. It includes: Asperger Syndrome, Classic Autism, Pervasive Developmental Disorder and Rett's syndrome. This means that the severity of the disability is different for different individuals. Studies on brain structure show that there is not one damaged area, but there are some of them. Based on the severity of the disorder and for practical reasons, autistic children belong to cathegories such as: Severe Autism; Mild Autism; Moderate Autism or Lowfunctioning Autism and High- functioning Autism. One of the most successful therapies used today is Applied Behaviour Analysis. Eventhough it is recomended to be used with all sub-cathegories of autistic children, the results are not always the same (Kurti, V. 2013). The therapies are the best solutions for children with autism spectrum disorder, but the tremendous truth, for parents, is that there is no cure for autism.

\section{Diferent parents, the same problem}

Globally speaking, the majority parents of autistic children seem to be alone, because there are some real obstacles that make them powerless. First of all, there are parents that are not aware of their children's rights. Two of the world laws on people rights are: Universal Declaration of Human Rights and Convention on the Rights of the child. Article 26 of the Universal Declaration of Human Rights guarantees "the right to education ...directed to the full development of the human personality and promot(ing) understanding, tolerance and friendship." OKB 1948

Convention on the Rights of the Child 1989 includes: 
"Recognizing the special needs of a disabled child ......to ensure that the disabled child has effective access to and receives education, training, health care services, rehabilitation services, preparation for employment and recreation opportunities in a manner conducive to the child's achieving the fullest possible social integration and individual development, encluding his or her cultural and spiritual development." Article 23

States Parties agree that the education of the child shall be directed to: "The development of the child's personality, talents and mental and physical abilities to their fullest potential. "Article 29 OKB 1989,

One of the most important battles for parents of autistic children has been integration of their children. The first schools for disable children were like islands. The children were isolated and they were not learning to get along with non-disabled students. One of the real winning cases for parents concerning their children integration was the Salamanca Statement. The Salamanca Statement of 1994 held in Spain adopted a new Framework for Action, the guiding principle of which was that ordinary schools should accommodate all children, regardless of their physical, intellectual, social, emotional, linguistic or other conditions. They agreed a dynamic new Statement on the education of all disabled children, which called for inclusion to be the norm. Salamanka statement

"...regular schools with this inclusive orientation are the most effective means of combating discriminatory attitudes, creating welcoming communities, building an inclusive society and achieving education for all; moreover, they provide an effective education to the majority of children and improve the efficiency and ultimately the cost-effectiveness of the entire education system".

The Salamanca Statement was the first global instrument explicitly calling for the inclusion of children with disabilities in regular education. Another instrument in December 2006 was the United Nations General Assembly that adopted the CRPD, ( Convention on the Rights of Persons with Disabilities), which secures the right to an inclusive education in international law. The CRPD does not simply recognize the right to inclusive education as an entitlement, but presents a framework of goals for inclusive education systems. It establishes obligations for governments and international agencies to provide the supports and conditions required to make quality inclusive education successful for all children and youth with disabilities. UNESCO (The United Nations Educational, Scientific and Cultural Organization) describes inclusive education as a process of addressing and responding to the diversity of needs of all learners through inclusive practices in learning, cultures and communities and reducing exclusion within and from education. It involves changes and modifications in content, approaches structures and strategies, with a common vision which covers all children of the appropriate age and a conviction that it is the responsibility of the regular system to educate all children (UNESCO, 2006). The disabled children now attend school in the same classrooms with non disabled children. But still there is a lot to do. To include an autistic child in a regular classroom means to improve the infrastructure needed in the classroom. This unresolved problem seems be the next battle of the parents of autistic children.

Secondly, parents are stigmatized about their child's disability. Especially in undeveloped countries, people suffer from prejudices. In addition, Autistic individuals are at extreme risk for bullying and abuse throughout their lives. A 2002 study from Comprehensive Issues in Pediatric Nursing found that 94 percent of students with Asperger Syndrome, are bullied Bulling can occur in schools, institutions or communities, even at home (Bulling and ASD).

Eventhough not all the parents are aware of their children' rights, on the other side, there are parents that have written books about autism. These parents are not afraid to talk freely about their children disorder. They try to explain what autism is, by using their experience. Tupe, E. (2009) as a father of an autistic child, prays to suffer for his child just to have his child "normal": "make me suffer, give me all the terrible diseases of the world- aids, lebbra, alzheimer, cancer, schizophrenia....just and only just Gesi be normal, are you listening, N-O-R-M-A-L!".

All parents dream is to have a normal child and they know that therapy is the only way to fulfill this dream. Most of them at the beginning meet a specialist to understand the opportunities their child could have if they follow the therapy. A mother of an autistic child Lala, B (2014) is aware of her child disability limits, but she never withdraws from the difficult road of "recovery": "In the afternoon I took him 3 times a week in development and psychomotor therapy" (Lala, B. 2014).

The attitude of parents towards autism depends on their culture, tradition, experience and economic status, but the same, main unsolved issue remains ' the future'. 


\section{Autistic individual as adult}

It seems that the focus of all studies is autistic individual as a child. This is a good point because the earlier the child get an accurate diagnose, the sooner his condition can be better. There are a lot of therapies that children can follow. Early Intervention Program is one of the most successful services used with children with Pervasive Developmental Delay in USA. If this program would be used in 1993 the number of autistic children would be smaller today (Kurti, V.2013). Specialists of the field that work with these children have seen a difference between children that are treated early with therapies and the other children that have never had therapies (Saqellari, S. 2011).

But let us think about those individuals that are over 18 years old. The picture is blurred and little is known about them. There is a gap between the information that comes from autistic children and autistic adults. One of the problems that parents of autistic children face every day is the future of their children. Autistic children cannot live independently and productively in the community and cannot live with the same freedom of choice as a non-disabled person. Sometimes they are violent, self -abusive and in many cases they do not behave properly.

Even though the Article 25 of human rights guarantees that:: "Everyone has the right to a standard of living adequate for the health and well-being of himself and of his family, including food, clothing, housing and medical care and necessary social services, and the right to security .........in circumstances beyond his control." for autistic individuals there are not many services to help them as adults. In USA the number of children expected to need extensive adult services by 2023 , will be more than 380.000 people. The cost of care for these people will be tremendous. Another problem is the services. Not everyone can take care of an autistic as adult. The caregiver should have the right qualities to take care of these disabled people and above all, the caregiver should be empathic. A mother of an adult autistic person gives us some clues: "When I look at my pudgy 22-year-old son, Randy...I wonder who will love or at least protect him when he ends up in a group home run by an underpaid, overworked staff". She admits that taking care of an autistic person is a real challenge and services in USA are dangerously strained: "Along with housing, day programs, transportation to those programs or jobs, and higher-than-average medical costs, adults with autism require steady supervision and support. Later she concludes:"This country urgently needs to focus on adult autism" (Davis, H.L.2009)

As the problem grows beyond USA, we have to consider thousand of parents worldwide that are distressed about their children future. In Albania 20 years ago the notion "autism" was unknown ( Saqellari, S. 2011). Today people are aware of this disorder but still there are no public services for autistic adults. There are some centers that use therapies and give support for autistic children with a modest staff of specialists on the field. There are no statistics about the number of autistic children and adults. Adult autistic families suffer in silence and pray for something to be done.

\section{Method}

The sample for the current study includes mothers, of autistic children diagnosed with Autism Spectrum Disorder (Asperger`s Disorder, Autistic Disorder, Rett's syndrome, Childhood Disintegrative Disorder, Pervasive Developmental Disorder, not otherwise specified) based on DSM-IV-TR (Diagnostic and Statistical Manual of Mental Disabilities). Parents are members of MEDPAK (Protect the Rights of Parents of Persons with Disabilities), a non-governmental organisation in Albania.

There were five interviews conducted with mothers of autistic children. Their children spend the most of the time at home. Economic conditions and social services were the main topic they were worried about, but above all, these mothers were desperate about the future of their children. The interviews were conducted in different days. The moderator gave an overview of the topic, made them sure that everyone point of view would be appreciated. They were made aware they were free to withdraw from the study at any time for any reason. After the moderator created a warm and friendly environment, confidentiality was ensured to all participants.

During the analysis process it was used the textual analysis, which includes a wide variety of things that can be analysed. The process of qualitative analysis aims to bring meaning to a situation rather than the search for truth focused on by quantitative research. In order to minimize the potential bias introduced in analysing and interpreting interviews data, Krueger \& Casey (2000) point out that the analysis should be systematic, sequential, verifiable, and continuous.

The first step was indexing and charting as a form to manage the data. It was used a computer-based approach for cutting, pasting, sorting, arranging and rearranging data through comparing and contrasting the relevant information. It was numbered each line of each transcript and two hard copies of each transcript were made; one to cut up and one that stays intact for later reference. Later the transcripts was printed on different colored paper to identify the groups. Then it was 
arranged the working transcript in a reasonable order, i.e. categories of participants: age, female. This arrangement helped the moderator to be alert to changes that maybe occurring from one person to another. At the end it was written on each page one of the questions to be analyzed. Because the author had several mothers, lines were drawn to divide the paper into sections and then comments within these sections. Later responses to the same question from all mothers responses were read. The author cut out relevant quotes and taped them to the appropriate place on the large sheet of paper. The quality of quotes varied. The unused quotes were left aside for later consideration. At the end of this process an overview was prepared integrating paragraph that described responses to that question. When this was finished, the author went to the next question, and so on.

For interpretation of coded data Krueger (1994) provides seven established criteria: words; context; internal consistency; frequency and extensiveness of comments; specificity of comments; intensity of comments; big ideas. First of all the moderator thought about the actual words used by the participants and the meanings of those words. The analyst needed to determine the degree of similarity between the responses. Later the analyst examined the context by finding the stimulus that triggered participants responses and interpreted the comment in light of the environment. Sometimes there was a shift in opinion and in order to discover the internal consistency, the researcher traced the flow of the conversation. The frequency relates to consideration of how often a comment is made. There were topics of special interest to participants. The conversation was not video- taped so the intensity was difficult to be spotted. Intensity is communicated by the voice tone, speed or emphases on different words. Based on specificity, responses that were specific and based on the first person experiences were given greater attention. Another thing to be considered by the analyst was 'big ideas'. Krueger (1994) suggests taking a break for a few days at this stage in order to refocus on the big picture.

During the interviews, mothers of autistic children expressed concern about their child life as adult: "I pray every day for my son. Some time I just want to die....but I have to live for my child. Who is going to help him? I don't want to imagine it...." Mother one

"I don't know, I don't have time to think about it. May be my other son will take care of his brother." Mother two

Some parents believe science can do miracles about disabilities.

"I hope there will be a solution for my daughter. .....You know science will do something."

There were even drastic decisions like: "...if I am going to die, he will come with me.... I love him too much to leave him alone."

\section{III.Conclusion}

This study aimed to understand the parent's point of view concerning their autistic children future. If we try to make a portrait of the situation concerning the autistic as adult, there would be a lot of feelings. The pesimistic one is what we cannot change. Having an autistic child is a burden not a parent can hold, especially when the diagnosis is low functioning autism. Autistic individuals are people that see the reality in a different way. It is our duty to understand, support and try to do our best about their future. At least we should explain our non-autistic children the situation. Eventhough the science is focusing on autistic children, about the factors that cause autism, or their school integration, the main issue remains autistic future. Autistic adults, belonging low functional autistic group, are in real threat. Parents of autistic children around the world seem to be suspicious about society and services. On the other hand, they cannot change the laws of nature and some day their children have to be alone. In this situation they just live for today and pray for the future.

\section{References}

[1] Bulling and ASD. Autistic self advocacy network. February,28.2012, Retrieved from http://autismnow.org/articles/bulling-and-autism-spectrum-disorder January 23.2016.

[2] Davis, H.L.2009 Still overlooking Autistic Adults. The Washington Post Retrieved from: http://www.washingtonpost.com/wp-dyn/content/article/2009. December 2015 
[3] Elsabbagh, M. et al.Global.2012. Prevalence of Autism and other PDD. Retrieved (October 2015), http://www.ncbi.nlm.nih.gov/autism/pmcp

[4] Krueger RA \& Casey MA (2000) Focus Groups: A Practical Guide for Applied Research, 3rd ed. Thousand Oaks, CA: SAGE Publication

[5] Krueger RA (1994) Focus Groups: A Practical Guide for Applied Research. Thousand Oaks, CA: Sage Publications.

[6] Kurti, V.2010.Autism.ADA.Tirane

[7] Kurti, V.2013. Autizmin e mësova nga ju. ADA. Tiranë

[8] Lala, B. 2014. ..Jeta ime me ty, për ty! Pegi, Tiranë

[9] OKB 1948, Deklarata Universale e të Drejtave të Njeriut.

[10] OKB 1989, Konventa për të drejtat e fëmijëve.

[11] Salamanka statement and framework for action. retrieved at: www.unesco.org/education/pdf/SALAMA_E.PDF

[12] Saqellari, S. 2011. Autizmi në këndveshtrimin psikoedukativ. Onufri,Tiranë

[13] Tupja, E. 2009. Kur dhimbja premton dashuri. Ombra GVG.Tiranë.

[14] UNESCO, 2006. Education for All, Global Monitoring Report (EFA).

[15] Vasta, R \& Haith, M. M \&Miller, A.S. Psikologjiae femijes.2007.EUGEN Tirane. 